\title{
Correction to: Climate Change Research, Policy and Actions in Indonesia
}

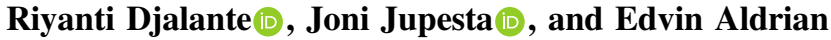

\section{Correction to:}

\section{R. Djalante et al. (eds.), Climate Change Research, Policy and Actions in Indonesia, Springer Climate, https://doi.org/10.1007/978-3-030-55536-8}

The original version of this book has been revised.

In the original version of chapter 9 , the reference section was omitted. This has now been rectified and the full reference section has been added below.

The original version of chapter 10 was previously published as non open access chapter. This has now been changed to open access under a CC BY 4.0 license, and the copyright holder for this chapter has been updated to "The Author(s)". The book has also been updated with these changes.

\section{References}

Abubakar I (dkk) (2009) Modul Pelatihan Agama dan Hak Asasi Manusia, CSRC UIN-Jakarta, Jakarta, hal. 23

Adolf H (1990) Aspek-aspek Negara Dalam Hukum Internasional, Rajawali Pers, Jakarta Agoes ER (Penyunting) (2000) Dimanahkah Batas-Batas Wilayah Kita Di Laut ?, Departemen Kelautan dan Perikanan, Jakarta, 13 Desember 2000.

Aldrian et al (2012) Perubahan Iklim Upaya Peningkatan Pengetahuan Dan Adaptasi Petani Dan Nelayan Melalui Radio, Indonesia Climate Change Trust Fund Badan Meteorologi,

Klimatologi Dan Geofisika Lembaga Ilmu Pengetahuan Indonesia, Sarana Komunikasi Utama, Bogor

The updated version of these chapters can be found at https://doi.org/10.1007/978-3-030-55536-8_9

https://doi.org/10.1007/978-3-030-55536-8_10

(C) Springer Nature Switzerland AG 2021

R. Djalante et al. (eds.), Climate Change Research, Policy and Actions in Indonesia, Springer Climate, https://doi.org/10.1007/978-3-030-55536-8_16 
Alwiah, Utina R (2013) Bapongka: Studi Nilai Pendidikan Pelestarian Ekosistem laut dan Pesisir pada Masyarakat Bajo

Artanto YK (2017) BAPONGKA, Sistem Budaya Suku Bajo Dalam Menjaga Kelestarian Sumber Daya Pesisir, Sabda 12(1), ISSN 1410-7910 E-ISSN 2549-1628, Juni 2017, hal. 52

Athena D, Anwar M (2007) Penelitian/Pengembangan Model/Sistem Surveilans Dampak Kesehatan Perubahan Iklim, Buletin Penelitian Kesehatan, vol 42, no 1, Jakarta, 2014, hal. 47-47. Lihat juga, IPCC, Climate Change Impacts, Adaptation and Vulnerability, Report of IPCC, Geneva, 2007, hal. 85-107

Athena D, Anwar M (2014) Penelitian/Pengembangan Model/Sistem Surveilans Dampak Kesehatan Perubahan Iklim, Buletin Penelitian Kesehatan, vol 42, no1, Jakarta

Aulia T, Dharmawan AH (2018) Kearifan Lokal Dalam Pengelolaan Sumber Daya Air Di Kampung Kuta, 2(2):345-355, https://download.portalgaruda.org/2010, (Diakses 25 April 2018). Lihat juga dalam Loc.cit., Mirnawati Firdaus, (diakses tanggal 25 April 2018). Lihat juga dalam Loc.cit., Yohanes Kristiawan Artanto, 2017, hal. 56

Ayatohaedi (ed) (1986) Kepribadian Budaya Bangsa (Local Genius), Pustaka Jaya, Jakarta hal 46s

Bachtiar I, Husni L, dan Romdiana (2018) Penyusunan Awig-Awig Pengelolaan Sumber Daya Perikanan di Pesisir Selatan kabupaten Lombok Timur, https://www.researchgate.net (diakses tanggal 26 Apr 2018)

Bahtiar (2012) Kearifan Lokal Orang Bajo Dalam Pengelolaan Sumber Daya Laut. Jurnal Mudra 27(2):178-185, ISSN 0854-3461. https://repo.isi-dps.ac.id/Bahtiar.pdf

Baskara B, Astuti O (2011) The Pamali of Wakatobi Bajo and its Role for Marine Conservation. J Indonesia Coral Reefs 1(2). https://coastalunhas.com/pdf. 2011, (Diakses 12 Januari 2018). Lihat juga dalam Op.Cit., Yohanes Kristiawan Artanto, 2017, hal. 54

Basuni S (2012) Mengelola Konservasi Sumberdaya Alam Hayati Berbasis Pengetahuan Tradisional dan Kearifan Lokal, Makalah Seminar Hasil-hasil penelitian Balai Penelitian Tekonologi Konservasi Sumberdaya Alam, 2012. (Diakses 12 Januari 2016). Lihat juga dalam Loc.cit., Yohanes Kristiawan Artanto, 2017, hal. 56

Dahuri (2001) Pengelolaan Ruang Wilayah Pesisir Dan Lautan Seiring Dengan Pelaksanaan Otonomi Daerah, Makalah ini disampaikan pada acara Semiloka dan Pelatihan Penataan Ruang Wilayah Propinsi, Kabupaten dan Kota Dalam Rangka Otonomi Daerah, kerjasama Bappeda Propinsi dan LPPM Unisba, Bandung, 2-3 Mei 2001, hal. 5

Diposaptono S, Budiman, Firdaus A (2009) Menyiasati Perubahan Iklim di Wilayah Pesisir dan Pulau-Pulau Kecil, Sarana Komunikasi Utama, Bogor (ID), 2009. Lihat juga, Loc.cit., Ari Wibowo, 2015, hal. 1

Finger M (2006) Which Governance for Sustainable Development? An Organizational and Institutional Perspective, dalam. In: Park J, Conca K, dan Finger M (eds) The crisis of global environmental governance: towards a new political economy of sustainability, Routledge Taylor \& Francis Group, New York, hal 125

Firdaus M (2017) Kearifan Lokal: Dari Tano Batak ke Maluku, hal. 1. Lihat juga Minarwati Firdaus, Kearifan Lokal Masyarakat Suku Bajo Di Sulawesi Tenggara Mendukung Kelestarian Sumber Daya kelautan dan Perikanan, https://www.penyuluhperikanan.id, 09 Januari 2017 (diakses tanggal 25 Apr 2018)

Gerungan LKFR (2016) Penegakan Hukum Di Wilayah Perairan Indonesia. Jurnal Lex et Societatis IV/No. 5/Mei, Fakultas Hukum Unsrat, Manado

Gusti Ngurah Jayanti I, Made Sumertha I, Ritual Dan Kepercayaan Masyarakat Pulau Bungin Kabupaten Sumbawa, Propinsi Nusa Tenggara Barat, https://varianwisatabudayasundakecil. blogspot.co.id, Rabu, 10 Desember 2014 (diakses tanggal 23 Apr 2018)

Hasanah A, Gustini N, Rohaniawati D (2016a) Nilai-nilai Karakter Sunda (Internalisasi Nilai-nilai Karakter Sunda di Sekolah), Deepublish, Jokyakarta, Juni 2016, hal. 42

Hasman FR (2009) Kekerabatan Masyarakat Bajou, Fak. Sastra Universitas Sumatera Utara, Medan, https://repository.usu.ac.id, 2009, (Diakses 25 April 2018). Lihat juga dalam Op.cit., Yohanes Kristiawan Artanto, 2017, hal. 55 
Hidayati D (2015) Adaptasi \& Mitigasi Masyarakat Pesisir Terhadap Perubahan Iklim dan Degradasi SDL, Adaptasi \& Mitigasi Masyarakat Pesisir, Leuser Cita Pustaka, Jakarta (ID), 2011, hal. 120-155. Lihat juga, Ibid., Ari Wibowo

Hidayati D, Aldrian E (dkk) (2012) Perubahan Iklim Upaya Peningkatan Pengetahuan Dan Adaptasi Petani Dan Nelayan Melalui Radio, Indonesia Climate Change Trust Fund Badan Meteorologi, Klimatologi Dan Geofisika Lembaga Ilmu Pengetahuan Indonesia, Sarana Komunikasi Utama, Bogor, 2012, hal. iii

Hidayati D, Deny (2011) Adaptasi \& Mitigasi Masyarakat Pesisir Terhadap Perubahan Iklim dan Degradasi SDL, Adaptasi \& Mitigasi Masyarakat Pesisir, Leuser Cita Pustaka, Jakarta (ID)

Indra-Fardhan. Kearifan Lingkungan Suku Bajo Dalam Pemanfaatan Pesisir Dan Laut Secara Berkelanjutan, https://dokumen.tips.html, 28 Sept 2015 (diakses tanggal 25 Apr 2018)

IPCC (2007) Climate change impacts, adaptation and vulnerability. Report of IPCC, Geneva

Kaligis OC (2003) \& Associates. Sengketa Sipadan-Ligitan, Mengapa Kita Kalah, Jakarta

Kementerian Agraria dan Tata Ruang/Badan Pertanahan Nasional, Rencana Strategis Direktorat Jenderal Tata Ruang 2015-2019, Jakarta, 2015, hal. 2.1

Keraf S (1997) Hukum Kodrat dan Teori Hak Milik Pribadi, Kanisius, Yogyakarta, hal. 16

Konvensi Perserikatan Bangsa-Bangsa Tentang Keanekaragaman Hayati, Terjemahan Resmi Salinan Naskah Asli

Lampe M (2011) Dinamika Kelembagaan Sosial Ekonomi Orang Bajo, Jagad Bahari Nusantara. https://centerformunawareducation.files.wordpress.com (Diakses 28 Apr 2018), Lihat juga dalam Ibid., Yohanes Kristiawan Artanto, 2017, hal. 56

Mahmassani S (1993) Konsep Dasar Hak-hak Asasi Manusia, Suatu Perbandingan Dalam Syariat Islam dan Perundang-undangan Modern, Tinta Mas, Jakarta, hal. 206

Makmur A (ed) (2011) Kearifan Lokal di Tengah Modernisasi, Pusat Penelitian dan Pengembangan Kebudayaan, Jakarta, 2011,. Lihat juga dalam Loc.cit., Yohanes Kristiawan Artanto, 2017, hal. 57

Marzuki PM (2005) Penelitian Hukum, Kencana Prenada Media Group, Jakarta, hal 93

Numberi F (2009) Perubahan Iklim: Implikasi terhadap Kehidupan di Laut, Pesisir dan Pulau-pulau Kecil, Citrakreasi Indonesia, Jakarta (ID), 2009. Ibid., Ari Wibowo, Lihat juga

Nurlaili (2012) Strategi Adaptasi Nelayan Bajo Menghadapi Perubahan Iklim: Studi Nelayan Bajo Di Kabupaten Sikka, Flores, Nusa Tenggara Timur. Jurnal Masyarakat \& Budaya 14(3) Tahun

Nurlaili (2012) Strategi Adaptasi Nelayan Bajo Menghadapi Perubahan Iklim: Studi Nelayan Bajo Di Kabupaten Sikka, Flores, Nusa Tenggara Timur. Jurnal Masyarakat \& Budaya 14(3):609611 (data tersebut diolah kembali)

NZ Human Rights, The rights of indigenous peoples: what you need to know. NZ Human Rights, New Zealand

Obie M (2016a) Perubahan Sosial Pada Komunitas Suku Bajo Di Pesisir Teluk Tomini, IAIN Sultan Amai Gorontalo. Jurnal Al-Tahrir 16(1):163

Paino C (2013) Lihat juga dalam Alwiah \& Ramli Utina, Bapongka: Studi Nilai Pendidikan Pelestarian Ekosistem laut dan Pesisir pada Masyarakat Bajo, 2013. https://repository.ung.ac.id (diakses tanggal 23 Apr 2018). Baca juga dalam Op.cit., Indra-Fardhan, (diakses tanggal 25 Apr 2018)

Paino C (2014) Kearifan Suku Bajo Menjaga Kelestarian Pesisir dan Laut, 26 Jan 2014, https:// www.mongabay.co.id (diakses tanggal 23 April 2018)

Park J, Conca K, Finger M (eds) (2006) The crisis of global environmental governance: towards a new political economy of sustainability. Routledge Taylor \& Francis Group, New York

Poedjowibowo D, Waani JO, Warouw F. Teritorialitas Pada Permukiman Suku Bajo Di Desa Tumbak (Studi Kasus Permukiman Diatas Air), jurnal yang tidak terpublikasikan, hal. 41. Lihat juga dalam www.indonesia.travel/suku-bajo-kisah-manusia-perahu-di-sulawesi

Pratikto AS, Hariadi MH, Aldrian E (dkk) Konsep Implementasi Adaptasi Sektoral Perubahan Iklim, Pusat Penelitian dan Pengembangan Badan Meteorologi, Klimatologi, dan Geofisika, Jakarta 
Pratikto AS, Hariadi MH, Aldrian dkk (Penulis) (2014) Konsep Implementasi Adaptasi Sektoral Perubahan Iklim, Pusat Penelitian dan Pengembangan Badan Meteorologi, Klimatologi, dan Geofisika, Jakarta, 2014, hal. 3

Primyastanto M (2015) Pengelolaan Sumber Daya Perikanan Melalui Kelembagaan Lokal Dalam Rangka Pemberdayaan Masyarakat Berbasis Kearifan Lokal di Pesisir Selat Madura, Gunung Samudra Cet. I, Malang, hal 14

Pusat (2005) Pengembangan Bahasa DEPDIKBUD, Kamus Besar Bahasa Indonesia, Balai Pustaka, Jakarta, hal 530

Raka Dalem GAA et al (2007) Kearifan Lokal dalam Pengelolaan Lingkungan Hidup, Cetakan Pertama, Pusat Penelitian Lingkungan Hidup (PPLH) UNUD, Denpasar, hal. 72

Rani M, Stalker P (2009b) Sisi Lain Perubahan Iklim: Mengapa Indonesia Harus Beradaptasi Untuk Melindungi Rakyat Miskinnya, UNDP-Indonesia, 2009, hal. 3. Lihat juga dalam Ibid., Nurlaili, 2012, hal. 614 (data tersebut diolah kembali)

Saad S (2009) Bajo Berumah di Laut Nusantara, CoremapII, Jakarta Selatan (ID), 2009, tanpa halaman. Lihat juga dalam Ari Wibowo, Strategi Adaptasi Dan Mitigasi Nelayan Di Pulau-Pulau Kecil Terhadap Dampak Perubahan Iklim, Laporan Studi Pustaka (KPM 403) Departemen Sains Komunikasi Dan Pengembangan Masyarakat Fakultas Ekologi Manusia Institut Pertanian Bogor, 2015, hal. 1

Sabarno H (2016) Pelaksanaan Administrasi Pemerintahan dan Pengelolaan Pulau-Pulau Indonesia di Wilayah Perbatasan. Dalam O.C. Kaligis \& Associates, Sengketa Sipadan-Ligitan, Mengapa Kita Kalah, Jakarta, 2003, hal. 60. Etty R. Agoes, (Penyunting), Dimanahkah Batas-Batas Wilayah Kita Di Laut?, Departemen Kelautan dan Perikanan, Jakarta, 13 Desember 2000, hal. 1. Lihat juga, Lusy K. F. R. Gerungan, Penegakan Hukum Di Wilayah Perairan Indonesia, Jurnal Lex et Societatis, Vol. IV/No. 5/Mei, Fakultas Hukum Unsrat, Manado, 2016, hal. 7

Salim E (2009) 3.000 Pulau Bakal Tenggelam, seminar Kelautan dan Perubahan Iklim, yang diselenggarakan Program Studi Ilmu Lingkungan Pascasarjana Universitas Indonesia bekerja sama dengan Direktorat Jenderal Kelautan Pesisir dan Pulau-pulau Kecil Departemen Kelautan dan Perikanan, Kamis (30 April 2009), Copyright-Badan Informasi Geospasial, https://www. big.go.id, Jakarta, 2009, hal. 1

Soemitro RH (1990) Metode Penelitian Hukum dan Jurimetri, Ghalia Indonesia, Jakarta, hal 36

Sudarja D (2007) Reformasi Pengelolaan Lingkungan Hidup, artikel, Pada Diskusi Membangun Gerakan Lingkungan Skepo, Walhi

Supriadi H (2008) Lingkungan di Indonesia: Sebuah Pengantar, Sinar Grafika, Jakarta, hal. 104107

Suryanegara E, Nahib I (2015) Perubahan Sosial Pada Kehidupan Suku Bajo: Studi Kasus Di Kepulauan Wakatobi, Sulawesi Tenggara, Majalah Globe vol 17, no 1

Suyuti N (1996) Kehidupan Sosial Budaya Komunitas Nelayan di Boenaga, Kabupaten Konawe, Sulawesi Tenggara, (Hasil Penelitian), Kerjasama FISIP UNHALU Depsos Sulawesi Tenggara di Desa Sulaho Kecamatan Lasusua Kabupaten Kolaka Utara, Kendari, tanpa halaman

Suyuti N (2011) Interaksi Orang Bajo dan Orang Bugis: dalam Konteks Kearifan Lokal-Global di Desa Sulaho, Kabupaten Kolaka Utara, Sulawesi Tenggara, Jagad Bahari Nusantara

Tahara T (2011) Politik Identitas Orang Bajo. Dalam: Yuga S (ed) Jagad Bahari Nusantara: Telaah Dinamika Pranata Sosial Terhadap Kearifan Lokal Masyarakat Pantai, Melestarikan Budaya Bahari dalam Pembangunan Kebudayaan dan Pariwisata, Kementerian Kebudayaan dan Pariwisata, Jakarta, 2011. Lihat juga dalam Ellen Suryanegara, Suprajaka, dan Irmadi Nahib, Perubahan Sosial Pada Kehidupan Suku Bajo: Studi Kasus Di Kepulauan Wakatobi, Sulawesi Tenggara, Majalah Globe Volume 17 No. 1 Juni 2015, hal. 74

Triadi BL, Gifariyono M (2014) Dampak Kenaikan Muka Air Laut Terhadap Kesesuaian Lahan Rawa Pasang Surut Tabunganen Kalimantan Selatan. Jurnal Sumber Daya Air, 10(2) Mei 2014, hal. 102

Wardana A (2007) Perusakan Lingkungan Sebagai Pelanggaran HAM, artikel, 2007, hal. 2

Wibowo A (2015) Strategi Adaptasi Dan Mitigasi Nelayan Di Pulau-Pulau Kecil Terhadap Dampak Perubahan Iklim, Laporan Studi Pustaka (KPM 403) Departemen Sains Komunikasi Dan Pengembangan Masyarakat Fakultas Ekologi Manusia Institut Pertanian Bogor 
Wibowo A, Arif S (2015) Strategi Adaptasi Nelayan di Pulau-Pulau Kecil terhadap Dampak Perubahan Iklim (Kasus: Desa Pulau Panjang, Kecamatan Subi, Kabupaten Natuna, Kepulauan Riau), Sodality: Jurnal Sosiologi Pedesaan, Agustus 2015

Wibowo A dan Satria A (2015) Strategi Adaptasi Nelayan di Pulau-Pulau Kecil terhadap Dampak Perubahan Iklim (Kasus: Desa Pulau Panjang, Kecamatan Subi, Kabupaten Natuna, Kepulauan Riau), Sodality: Jurnal Sosiologi Pedesaan, Agustus 2015, hal. 107-124

Widayatun et al (2011) Adaptasi dan Mitigasi Masyarakat Pesisir Terhadap Perubahan Iklim dan Degradasi, PPK-LIPI, Jakarta

Zacot (1979) dalam Nasruddin Suyuti, Interaksi Orang Bajo dan Orang Bugis: dalam Konteks Kearifan Lokal-Global di Desa Sulaho, Kabupaten Kolaka Utara, Sulawesi Tenggara, Jagad Bahari Nusantara, 2011, https://centerformunawareducation.files.wordpress.com (diakses tanggal 23 April 2018). Dalam Loc.cit., Indra-Fardhan, (diakses tanggal 25 April 2018)

Zuliansyah (2010) Kelestarian Lingkungan Hidup Sebagai Hak Asasi Manusia, artikel, Kementerian Hukum dan Hak Asasi Manusia, Direktorat Jenderal Hak Asasi Manusia 20 Sept 2010 